\title{
Erratum to: Regional Meteorological Patterns for Heavy Pollution Events in Beijing
}

\author{
Ting YOU ${ }^{1,2}$, Renguang $\mathrm{WU}^{2,3^{*}}$, Gang HUANG ${ }^{3,4,5,6}$, and Guangzhou FAN ${ }^{1}$ \\ 1 College of Atmospheric Sciences, Chengdu University of Information Technology, Chengdu 610225 \\ 2 Center for Monsoon System Research, Institute of Atmospheric Physics, Chinese Academy of Sciences, Beijing 100029 \\ 3 State Key Laboratory of Numerical Modeling for Atmospheric Sciences and Geophysical Fluid Dynamics, \\ Institute of Atmospheric Physics, Chinese Academy of Sciences, Beijing 100029 \\ 4 Laboratory for Regional Oceanography and Numerical Modeling, Qingdao National Laboratory for \\ Marine Science and Technology, Qingdao 266237 \\ 5 Joint Center for Global Change Studies, Beijing 100875 \\ 6 University of Chinese Academy of Sciences, Beijing 100049
}

(Received April 19, 2018; in final form June 5, 2018)

Citation: You, T., R. G. Wu, G. Huang, et al., 2018: Erratum to: Regional meteorological patterns for heavy pollution events in Beijing. J. Meteor. Res., 32(3), 516-516, doi: 10.1007/s13351-018-8999-0.

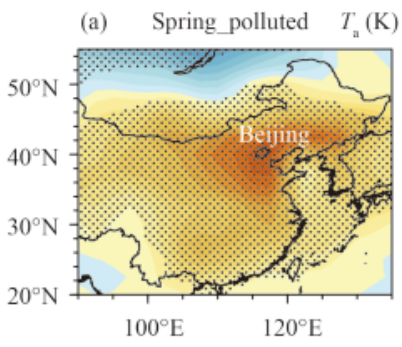

(c) Summer polluted $T_{0}(\mathrm{~K})$

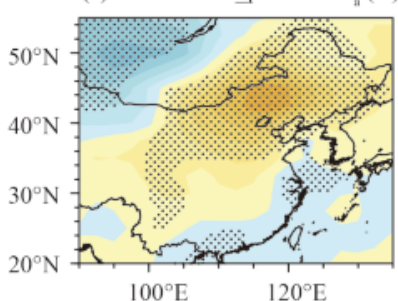

(e) Fall_polluted

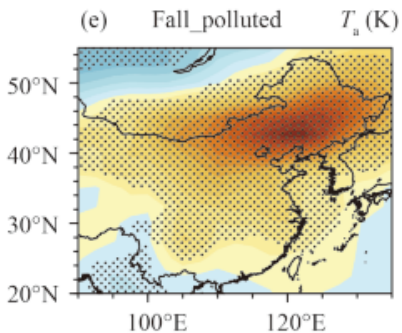

(g) Winter polluted $T_{n}(\mathrm{~K})$

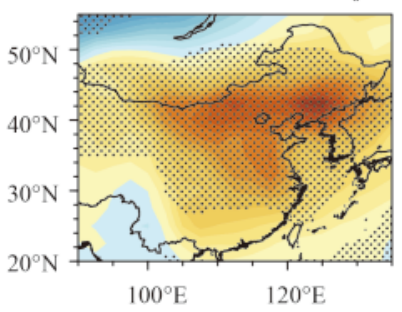

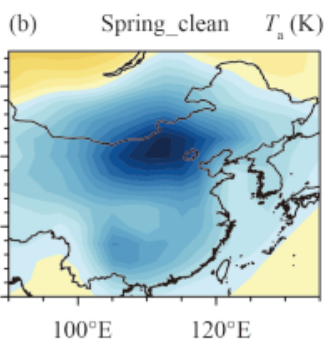

(d) Summer_clean $T_{\mathrm{a}}(\mathrm{K})$
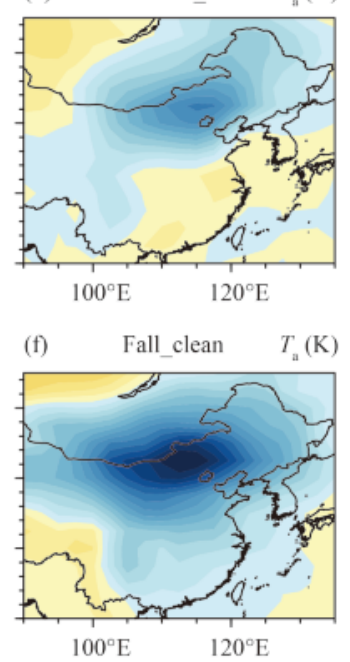

(h) Winter_clean $T_{\mathrm{n}}(\mathrm{K})$

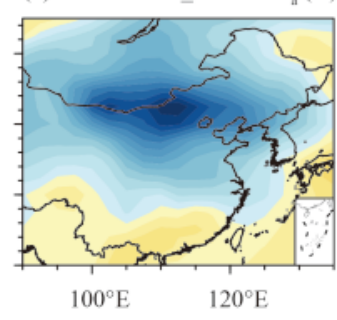

*Corresponding author: renguang@mail.iap.ac.cn.

(C) The Chinese Meteorological Society and Springer-Verlag Berlin Heidelberg 2018 